\title{
Inventory and Credit Decisions under Day-Terms Credit Linked Demand and Allowance for Bad Debts
}

\author{
K. K. Aggarwal and Arun Kumar Tyagi \\ Department of Operational Research, Faculty of Mathematical Sciences, University of Delhi, Delhi 110007, India
}

Correspondence should be addressed to Arun Kumar Tyagi; aruntyagi.du@gmail.com

Received 28 July 2014; Accepted 26 October 2014; Published 8 December 2014

Academic Editor: Jen-Chih Yao

Copyright ( 2014 K. K. Aggarwal and A. K. Tyagi. This is an open access article distributed under the Creative Commons Attribution License, which permits unrestricted use, distribution, and reproduction in any medium, provided the original work is properly cited.

\begin{abstract}
In order to stimulate demand of their product, firms generally give credit period to their customers. However, selling on credit exposes the firms to the additional dimension of bad debts expense (i.e., customer's default). Moreover, credit period through its influence on demand becomes a determinant of inventory decisions and inventory sold on credit gets converted to accounts receivable indicating the interaction between the two. Since inventory and credit decisions are interrelated, inventory decisions must be determined jointly with credit decisions. Consequently, in this paper, a mathematical model is developed to determine inventory and credit decisions jointly. The demand rate is assumed to be a logistic function of credit period. The accounts receivable carrying cost along with an explicit consideration of bad debt expense which have been often ignored in previous models are incorporated in the present model. The discounted cash flow approach (DCF) is used to develop the model and the objective is to maximize the present value of the firm's net profit per unit time. Finally, numerical example and sensitivity analysis have been done to illustrate the effectiveness of the proposed model.
\end{abstract}

\section{Introduction}

The basic purpose of a firm is maximization of its present value and in order to achieve this goal proper inventory management is an important aspect. The basic objective of any inventory control system is to satisfy the future demand in a best possible manner. The classical EOQ model assumes that demand cannot be influenced by the decision maker. However, decision maker can influence the demand by giving credit period to its customers. Trade credit is used by the firms as a marketing strategy to stimulate demand by attracting the customers who consider it to be a type of price reduction. Moreover, to realize sales from customers who do not have money for instant payment the firm must wait until they resell the goods before doing the payment. Many customers would like to verify the quality of firm's product prior to making the payment. In such circumstances, firm allows sales on credit so that it can sell more goods in comparison to when it relies only on cash sales. Teng [1] also illustrated two benefits of trade credit policy to the supplier: (1) it should attract new customers who consider it to be a type of price reduction;
(2) it should cause a reduction in the sales outstanding, since some established customers will pay more promptly in order to take advantage of permissible delay more frequently. The two common forms of trade credit are day-terms and dateterms. In day-terms credit payment has to be done within a fixed time period after a purchase and in date-terms credit the firm specifies a due date on which payment has to be done (Kingsman [2], Carlson and Rousseau [3], Robb, and Silver [4]). Thus, in day-terms credit each customer gets same amount of credit period irrespective of its purchase date, while in date-terms credit policy the credit period availed by the customers is the difference between due date (i.e., maximum credit period) and the time at which customer has purchased the goods.

The response of demand rate with respect to credit period will have a significant impact on the decision making. In a credit elastic market, credit period is supposed to increase demand of the product by inducing existing customer to order larger quantity and attracting new customers. The net effect of these will be reflected in the demand rate. Since in reality the market consists of customers having different 
financial capacities so their propensity towards availing credit period would also be different. For example, a low value of credit period has utility only for customers having low income while a larger value of credit period would also be worth full to high income customers along with the low income customers. Therefore, at first demand increases slowly with the increase in credit period but as credit period increases further the demand rate increases substantially in view of the fact that credit period has now value to a large number of customers. But the demand rate cannot increase indefinitely with the increase in credit period as there is a limit to this growth due to the finite market potential. Consequently, the demand rate will eventually reach its saturation level after a certain value of credit period. Hence, in general, as credit period increases, the demand rate at first increases slowly, then there is a substantial increase in its value, and finally reaches its saturation level due to finite market potential. The growth curve of demand rate under such circumstances can be represented by the sigmoid or Sshaped pattern (e.g., logistic function), when demand rate is plotted against credit period (Figure 1).

The logistic curve consists of three different patterns, $A B$, $B C$, and $C D$. From $A$ to $B$ the curve gradually rises, from $B$ to $\mathrm{C}$ it is almost an exponential increase, and from $\mathrm{C}$ to $\mathrm{D}$ it gets flattened. It implies that at smaller value of credit period the demand effect of credit period is less (AB), after that as credit period increases the demand effect of credit period increases significantly $(\mathrm{BC})$ and then gradually saturates to its maximum level with a further increase in credit period (CD).

The credit policy through its impact on demand becomes a determinant of inventory policy. Moreover, when inventories are sold on credit, they get converted into accounts receivable. The close interaction among these components implies that the optimal policy for one component cannot be determined without the simultaneous consideration of other component. The inventory policy sets the timing and quantity of cash outflows, while credit policy sets the timing and quantity of cash inflows. Because of the link among their associated cash flows, the inventory and credit decisions will have an effect on each other. Since inventory and credit decisions are interrelated, inventory decisions must be determined jointly with the credit decisions. However, inventory decisions are normally determined independently of the credit decisions.

Furthermore, when a firm allows sales on credit it results in increased revenue as well as causing certain costs to the firm. Selling on credit will be economical for the firm if the revenue generated due to credit sales is sufficient to compensate the cost of giving trade credit. Goods sold on credit get converted to accounts receivables whose accumulation would result in accounts receivable carrying cost to the firm. The costs associated with carrying accounts receivables are the cost of financing accounts receivable, administrative costs in running a credit department, delinquency or collection costs, and cost of default by the customers, that is, bad debt losses. Out of the total cost in granting credit period the most significant cost is uncollectible accounts or bad debts. This is due to the fact that selling on credit exposes the firm to the additional dimension of default risk (i.e., nonpayment)

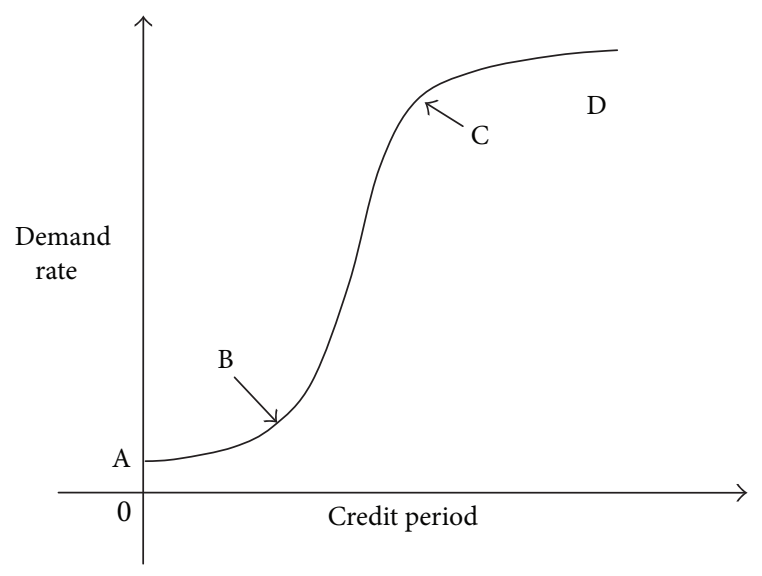

FIgURE 1: (Logistic curve).

from the customers as some customers are either unable or unwilling to pay. If a customer declares bankruptcy, no payment may be forthcoming. If the customer leaves the city or the state, it may be too costly to trace him and demand payment. In these cases, the firm is forced to accept a baddebt loss on the account. Most firms expect to incur baddebt losses in the normal course of business. These losses are properly viewed as a cost of administering a credit policy. If the firm can identify such nonpaying customers in advance then it would refuse to trade with them except on a cash basis. Since the firm cannot identify such customers beforehand so this loss may be a necessary loss of business. It is the cost which must be sustained in order to obtain the profit from the paying customers. Hence, the bad-debt expenses need to be given an explicit consideration in decision making.

Although the firm cannot distinguish between the paying and nonpaying customers in advance, sometimes from past experiences the firm knows with a reasonable degree of certainty that a number representing a certain portion of accounts receivable will never be collected, and hence that much amount must be written off from the profit. Since the matching principle of accrual accounting requires the recognition of bad debts expense at the same time as the related revenue; therefore, in order to record and measure the accounts uncollectible, the firm usually uses allowance method for bad debt losses as it confirms the matching principle of accrual accounting. In this method, the firm makes an estimate of the portion of credit sales that will ultimately be uncollectible from as yet unidentified customers. Consequently, the firms usually express the amount of bad debts as a percentage of total credit sales, which relies on the historical relationship between credit sales and uncollectible debts, that is, which depends on the past experience of the firm.

Owning to the fact that credit period has an influence on the demand K. K. Aggarwal and S. P. Aggarwal [5] developed an EOQ model with credit linked demand when firm purchases items on cash in an inflationary condition. Jaggi et al. [6] expanded on this theme and developed an EOQ model with trade credit linked demand under the two stage trade credit financing. However, in these models 
the credit period is assumed to be given and only ordering decisions were determined. Other relevant articles with credit linked demand dealing with inventory or inventory and credit decisions are Su et al. [7], Jaggi et al. [8], Thangam and Uthayakumar [9], Maiti [10], Ho [11], Annadurai and Uthayakumar [12], Giri and Maiti [13], and Shah et al. [14].

All the above mentioned articles have ignored the cost of granting credit period to customers and none of them have assumed demand rate to be a logistic function of credit period. In addition, average cost approach was used in developing all the aforementioned models with the exception of K. K. Aggarwal and S. P. Aggarwal [5], Jaggi et al. [6], and Maiti [10]. In average cost approach the time value of money is not explicitly taken into account and there is no distinction between out-of-pocket holding cost and opportunity costs due to investment of funds in inventory as well as in accounts receivable. Moreover, the effect of delayed revenue realization because of credit period given to customers cannot be captured by the average cost approach. It is widely accepted that the net present value or DCF approach leads to a better decision (Kim and Feist [15]). The DCF approach allows proper recognition of the financial implication of the opportunity cost and out-of-pocket costs associated with the economic system. It also permits an explicit recognition of the exact timing of each cash-flow associated with the economic system and considers the time value of money.

Consequently, in this paper, a mathematical model is developed within the discounted cash flow approach to determine optimal inventory and credit period decisions jointly for a firm. The firm purchases a single product on cash and sells on day-terms credit to its customers. The demand rate has been modeled as a logistic function of credit period. The cost of carrying accounts receivable along with the explicit consideration of the allowance for bad debt expense is considered. The objective is to maximize the present value of firm's net profit per unit time. A hypothetical numerical example, sensitivity analysis, and observations are presented to illustrate the effectiveness of the proposed model.

\section{Notations and Assumptions}

2.1. Notations. The notations used in this paper are as follows:

$Q=$ Ordering quantity per order

$T=$ Inventory cycle time (in years)

$N=$ Credit period given by the firm (in years)

$d(N)=$ Demand rate (in units/year)

$f=$ Proportion of credit sales that becomes bad debts

$\mathrm{O}=$ Ordering cost per order (in dollars)

$C=$ Unit purchase cost (in dollars)

$P=$ Unit selling price (in dollars)

$k=$ Rate of interest or discount rate per year (in percent per year)

$I=$ Out-of-pocket inventory carrying cost per year, as a percentage of unit purchase cost
$R=$ Out-of-pocket receivable carrying cost per year, as a percentage of unit selling price

$I(t)=$ Inventory level at any time " $t$ "

$R(t)=$ Accounts receivable level at any time " $t$ "

$Z(N, T)=$ Net profit per year as a function of decision variables " $N$ " and " $T$."

2.2. Assumptions. The model has been developed under the following assumptions.

(1) Inventory system involves one type of item.

(2) Firm purchases on cash and sells on credit.

(3) The firm offers same amount of credit period to each of its credit customers. Thus, firm follows a day-terms credit policy, that is, net $N$, where $N$ is the credit period.

(4) The demand rate is a function of the credit period offered by the firm. Under the assumption that "demand rate first increases slowly, then increases substantially, and after that saturates as credit period increases" the demand rate function without the loss of generality can be described by the logistic function $d(N)=d_{m} /\left(1+a e^{-b N}\right)$, where $a>0, b>0$, are constants and $d_{m}$ is the maximum achievable demand rate, that is, upper bound on the demand rate. Figure 2 depicts several logistic curves for various values of growth parameter $b$ with $d_{m}=10,000$ and $a=15$ are depicted.

(5) The effect of credit policy on demand is observed instantaneously without any delay.

(6) A certain portion of accounts receivable of the firm remains uncollectible; that is, the firm incurs bad debt loss whose proportion out of the total credit sales is known to the firm. The proportion of credit sales that becomes bad-debt loss can be estimated from the past data of credit sales and accounts uncollectible.

(7) All the nondefaulting customers settle their account timely.

(8) Replenishment rate is infinite.

(9) Shortages are not allowed.

(10) Lead time is zero or negligible.

(11) Discounted cash flow approach is used to reflect the time value of money.

\section{Mathematical Modeling}

At the start of the cycle, the inventory level is raised to $Q$ units; afterwards as time progresses, the level of inventory decreases to fulfill demand up to " $T$ " and becomes zero at " $T$ " (Figure 3).

There is a cash outflow of ordering and purchase cost at the start of cycle and the revenue from credit sales taking place during the replenishment interval will be received by the firm from " $N$ " to " $T+N$ " (Figure 4). 


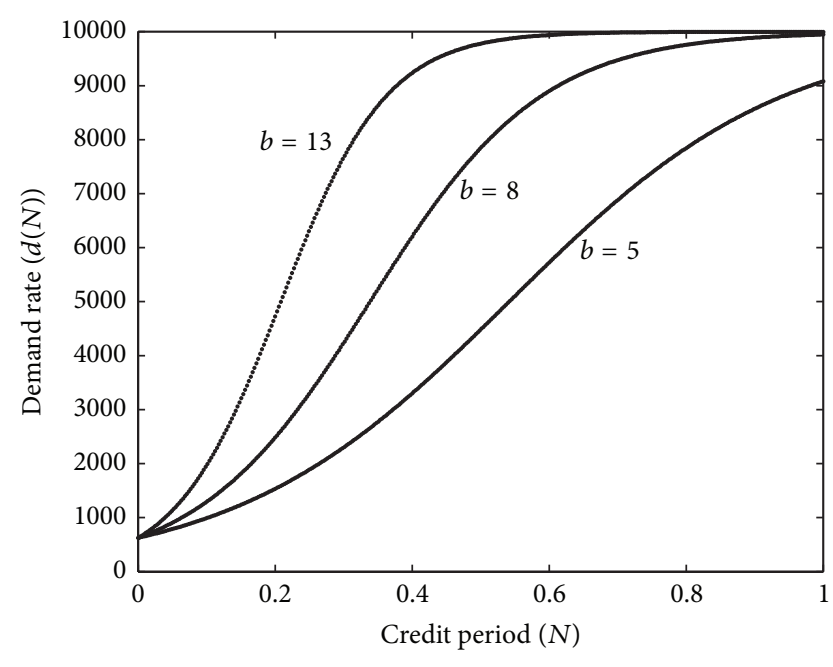

Figure 2: Demand rate versus credit period.

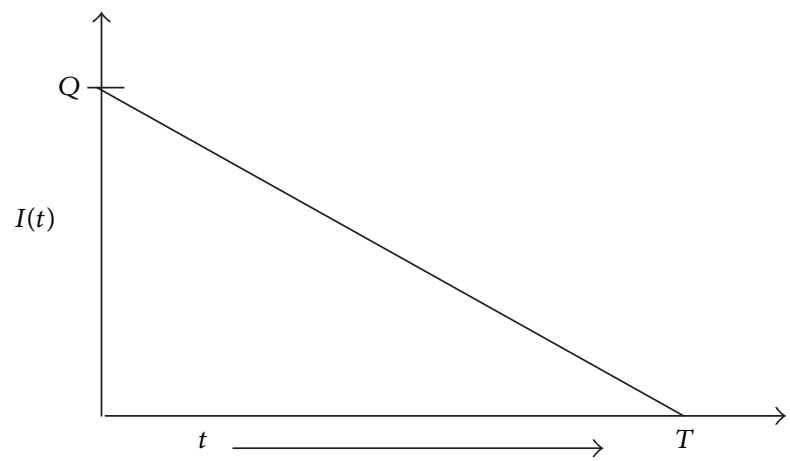

FIGURE 3: Inventory level versus time.

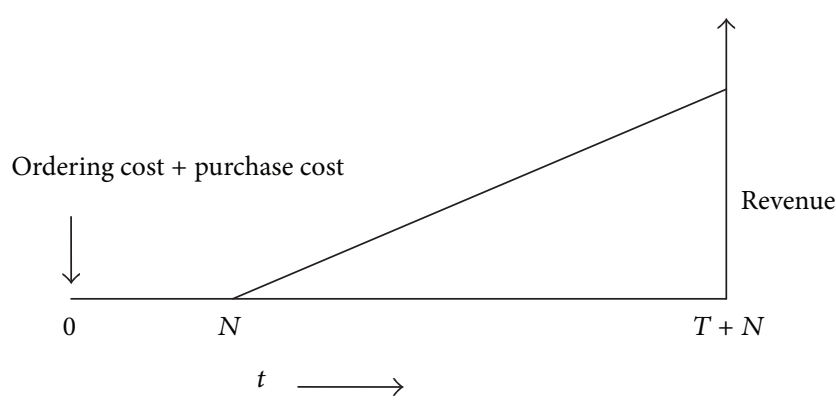

FIGURE 4

For the firm, the present value of its net profit per year $Z(N, T)$ can be expressed as

$Z(N, T)=$ Revenue from sales - Ordering cost

- Purchase cost - Inventory carrying cost (1)

- Accounts receivable carrying cost.
Since replenishment rate is infinite and shortages are not allowed, so the initial inventory level, $I(0)$ (i.e., the order quantity, $Q$ ) is

$$
I(0)=Q=\int_{0}^{T}\left(\frac{d_{m}}{1+a e^{-b N}}\right) d t=\frac{d_{m} T}{1+a e^{-b N}} .
$$

And the variation of inventory level with respect to time can be described by the following differential equation:

$$
\frac{d I(t)}{d t}=-\left(\frac{d_{m}}{1+a e^{-b N}}\right) \quad 0 \leq t \leq T
$$

With the boundary conditions: $I(0)=Q=d_{m} T /\left(1+a e^{-b N}\right)$ and $I(T)=0$, consequently, the solution of (3) is given by

$$
I(t)=\frac{d_{m}}{1+a e^{-b N}}(T-t), \quad 0 \leq t \leq T .
$$

Furthermore, the level of accounts receivable at any time " $t$ " depends upon the sales rate and the rate of revenue collection at that point of time. As the collection of revenue corresponding to the sales which take place during the inventory cycle, that is, from " 0 " to " $T$ " will occur from " $N$ " to " $T+N$ ", therefore, calculation for the level of accounts receivable will depend upon the following cases, namely, (1) $N \leq T$ (Figure 5) and (2) $N \geq T$ (Figure 6), which are explained in the subsequent sections.

By using DCF approach, the various components of the profit functions are as follows:

The present value of revenue per year from sales

$$
\begin{aligned}
& =\frac{(1-f) P}{T}\left(\int_{N}^{T+N}\left(\frac{d_{m}}{1+a e^{-b N}}\right) e^{-k t} d t\right) \\
& =\frac{(1-f) P d_{m} e^{b N-k(N+T)}\left(e^{k T}-1\right)}{\left(a+e^{b N}\right) k T},
\end{aligned}
$$

The present value of the ordering cost per year

$$
=\frac{O}{T},
$$

The present value of purchasing cost per year

$$
=\frac{C Q}{T}=\frac{C}{T}\left(\frac{d_{m} T}{1+a e^{-b N}}\right)=\frac{C d_{m}}{1+a e^{-b N}},
$$

The present value of inventory carrying cost per year

$$
\begin{aligned}
& =\frac{I C}{T} \int_{0}^{T} I(t) e^{-k t} d t=\frac{I C}{T} \int_{0}^{T}\left(\frac{d_{m}(T-t)}{1+a e^{-b N}}\right) e^{-k t} d t \\
& =\frac{I C d_{m} e^{b N}\left(e^{-k T}+k T-1\right)}{\left(a+e^{b N}\right) k^{2} T} .
\end{aligned}
$$

The calculation of accounts receivable carrying cost will depend upon the following cases. 


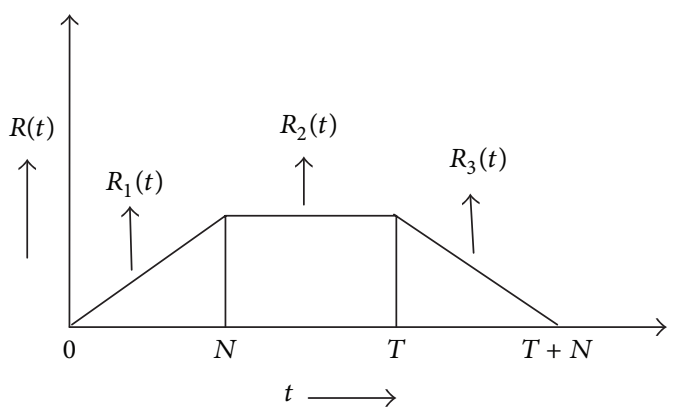

FIGURE 5: Accounts receivable versus time.

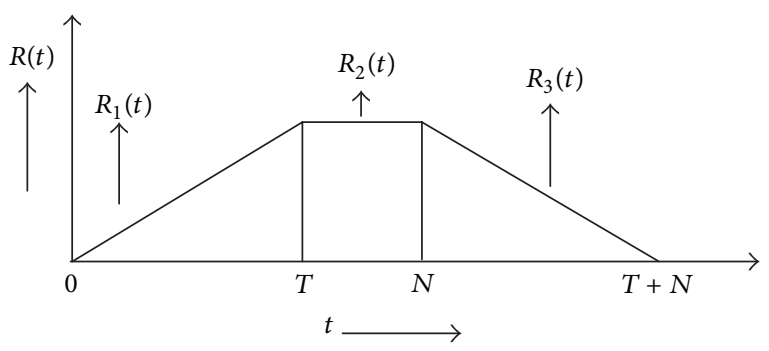

FIGURE 6: Accounts receivable versus time.

Case $1(N \leq T)$. Taking into account the credit sales that occur during the replenishment interval, we observe that the behavior of the level of accounts receivable will be as follows: at the start of the cycle, the level of accounts receivable is zero; afterwards as time progresses it accumulates up to $N$ due to credit sales. From $N$ to $T$, two things happen simultaneously; that is, the accounts receivable are created as a result of credit sales and also the accounts receivables are collected by the firm. Since the rate of credit sales is equal to the rate of collection of accounts receivable, the net level of accounts receivable remains constant for $N \leq t \leq T$. From $T$ to $T+N$ the level of accounts receivable decreases due to their collection and becomes zero at $T+N$. The accounts receivable created from $T$ to $T+N$ will be accounted in next cycle.

Let

$R(t)=\left\{R_{1}(t)=\right.$ accounts receivable level at any time $t$,

$$
\text { for } 0 \leq t \leq N \text {, }
$$

$R_{2}(t)=$ accounts receivable level at any time $t$,

$$
\text { for } N \leq t \leq T \text {, }
$$

$R_{3}(t)=$ accounts receivable level at any time $t$,

$$
\text { for } T \leq t \leq T+N\} \text {. }
$$

We have

$R_{1}(t)=0+\int_{0}^{t}\left(\frac{d_{m}}{1+a e^{-b N}}\right) d t=\frac{d_{m} t}{1+a e^{-b N}}, \quad 0 \leq t \leq N$,

$$
\begin{aligned}
R_{2}(t)= & \int_{0}^{N}\left(\frac{d_{m}}{1+a e^{-b N}}\right) d t \\
& +\int_{N}^{t}(\text { Sales rate }- \text { Collection rate }) d t \\
= & \int_{0}^{N}\left(\frac{d_{m}}{1+a e^{-b N}}\right) d t \\
& +\int_{N}^{t}\left(\frac{d_{m}}{1+a e^{-b N}}-\frac{d_{m}}{1+a e^{-b N}}\right) d t \\
= & \left(\frac{d_{m} N}{1+a e^{-b N}}\right), \quad N \leq t \leq T,
\end{aligned}
$$

$$
\begin{aligned}
R_{3}(t) & =\int_{t}^{T+N}\left(\frac{d_{m}}{1+a e^{-b N}}\right) d t \\
& =\left(\frac{d_{m}}{1+a e^{-b N}}\right)(T+N-t), \quad T \leq t \leq T+N,
\end{aligned}
$$

The present value of account receivables carrying cost per year

$$
\begin{gathered}
=\frac{R P}{T}\left(\int_{0}^{N} R_{1}(t) e^{-k t} d t\right. \\
\left.\quad+\int_{N}^{T} R_{2}(t) e^{-k t} d t+\int_{T}^{T+N} R_{3}(t) e^{-k t} d t\right) \\
=\frac{R P}{T}\left(\int_{0}^{N}\left(\frac{d_{m} t}{1+a e^{-b N}}\right) e^{-k t} d t\right. \\
\quad+\int_{N}^{T}\left(\frac{d_{m} N}{1+a e^{-b N}}\right) e^{-k t} d t \\
\left.\quad+\int_{T}^{T+N}\left(\frac{d_{m}}{1+a e^{-b N}}\right)(T+N-t) e^{-k t} d t\right) \\
=\frac{R P}{T}\left(\frac{d_{m} e^{(b-k) N}\left(e^{k N}-k N-1\right)}{\left(a+e^{b N}\right) k^{2}}\right. \\
\quad+\frac{d_{m} e^{b N}\left(e^{-k N}-e^{-k T}\right) N}{\left(a+e^{b N}\right) k} \\
\left.\quad+\frac{d_{m} e^{-k(N+T)}\left(1+e^{k N}(k N-1)\right)}{\left(1+a e^{-b N}\right) k^{2}}\right) .
\end{gathered}
$$

Using (5) and (10), the present value of firm's net profit per year, $Z_{1}(N, T)$ is

$$
\begin{aligned}
Z_{1}(N, T)=[ & \frac{(1-f) P d_{m} e^{b N-k(N+T)}\left(e^{k T}-1\right)}{\left(a+e^{b N}\right) k T} \\
& -\frac{O}{T}-\frac{C d_{m}}{1+a e^{-b N}} \\
& -\frac{I C d_{m} e^{b N}\left(e^{-k T}+k T-1\right)}{\left(a+e^{b N}\right) k^{2} T} \\
& -\frac{R P}{T}\left(\frac{d_{m} e^{(b-k) N}\left(e^{k N}-k N-1\right)}{\left(a+e^{b N}\right) k^{2}}\right.
\end{aligned}
$$




$$
\begin{aligned}
& +\frac{d_{m} e^{b N}\left(e^{-k N}-e^{-k T}\right) N}{\left(a+e^{b N}\right) k} \\
& \left.\left.+\frac{d_{m} e^{-k(N+T)}\left(1+e^{k N}(k N-1)\right)}{\left(1+a e^{-b N}\right) k^{2}}\right)\right]
\end{aligned}
$$

The necessary conditions for the maximization of $Z_{1}(N, T)$ are

$$
\frac{\partial Z_{1}(N, T)}{\partial N}=0, \quad \frac{\partial Z_{1}(N, T)}{\partial T}=0
$$

which gives

$$
\begin{aligned}
& {\left[\frac{P d_{m} e^{b N-k(N+T)}\left(e^{k T}-1\right)(f-1)\left(e^{b N} k+a(k-b)\right)}{\left(a+e^{b N}\right)^{2} k T}\right.} \\
& -\frac{\operatorname{Cabd}_{m} e^{-b N}}{\left(1+a e^{-b N}\right)^{2}}-\frac{\operatorname{ICabd}_{m} e^{b N-k T}\left(1+e^{k T}(k T-1)\right)}{\left(a+e^{b N}\right)^{2} k^{2} T} \\
& -\frac{R P d_{m} e^{(b-k) N}\left(e^{b N} k^{2} N+a\left(k^{2} N+b\left(e^{k N}-k N-1\right)\right)\right)}{\left(a+e^{b N}\right)^{2} k^{2} T} \\
& +\left(R P d_{m} e^{b N-k(N+T)}\right. \\
& \times\left(e^{b N}\left(e^{k N}+e^{k T}(k N-1)\right)\right. \\
& +a\left(e^{k N}(1+b N)\right. \\
& \left.\left.+e^{k T}(k N-b N-1)\right)\right) \\
& \left.\times\left(\left(a+e^{b N}\right)^{2} k T\right)^{-1}\right) \\
& -\left(R P d_{m} e^{b N-k(N+T)}\right. \\
& \times\left(e^{b N}\left(e^{k N}-1\right) k\right. \\
& +a(b-k \\
& \left.\left.+e^{k N}(k+b(k N-1))\right)\right) \\
& \left.\left.\times\left(\left(a+e^{b N}\right)^{2} k^{2} T\right)^{-1}\right)\right]=0, \\
& {\left[\left(\frac{d_{m} e^{b N-k(N+T)}(f-1) P\left(e^{k T}-k T-1\right)}{\left(a+e^{b N}\right) k T^{2}}\right)\right.} \\
& +\left(\frac{O}{T^{2}}\right)-\left(\frac{I C d_{m} e^{b N-k T}\left(e^{k T}-k T-1\right)}{\left(a+e^{b N}\right) k^{2} T^{2}}\right) \\
& -\left(\frac{P R d_{m} e^{(b-k) N}\left(1-e^{k N}+k N\right)}{\left(a+e^{b N}\right) k^{2} T^{2}}\right) \\
& -\left(\frac{R P d_{m} e^{b N-k(N+T)} N\left(e^{k N}(1+k T)-e^{k T}\right)}{\left(a+e^{b N}\right) k T^{2}}\right)
\end{aligned}
$$

$$
\begin{aligned}
& \left.+\left(\frac{R P d_{m} e^{b N-k(N+T)}\left(1+e^{k N}(k N-1)\right)(1+k T)}{\left(a+e^{b N}\right) k^{2} T^{2}}\right)\right] \\
& =0 .
\end{aligned}
$$

The solution of above equations gives the optimal values of $N$ and $T$ for the maximization of $Z_{1}(N, T)$ provided that they satisfy the sufficiency conditions given by

$$
\begin{aligned}
& \frac{\partial^{2} Z_{1}}{\partial N^{2}} \leq 0, \quad \frac{\partial^{2} Z_{1}}{\partial T^{2}} \leq 0, \\
& \left(\frac{\partial^{2} Z_{1}}{\partial N^{2}}\right)\left(\frac{\partial^{2} Z_{1}}{\partial T^{2}}\right)-\left(\frac{\partial^{2} Z_{1}}{\partial N \partial T}\right)^{2} \geq 0 .
\end{aligned}
$$

However, it is difficult to solve the necessary conditions analytically in a closed form and also to check the validity of sufficient conditions analytically. Consequently, numerical approach is used to obtain the solution.

Case $2(N \geq T)$. Taking into account the credit sales that occur during the replenishment interval, we observe that the behavior of the level of accounts receivable will be as follows: at the start of the cycle, the level of accounts receivable is zero; afterwards as time progresses it accumulates up to $T$ due to credit sales and remains at this level up to $N$. From $N$ to $T+N$ the level of accounts receivable decreases due to their cash realization and becomes zero at $T+N$. The accounts receivable created from $T$ to $T+N$ will be accounted in next cycle.

Let

$R(t)=\left\{R_{1}(t)=\right.$ accounts receivable level at any time $t$,

$$
\text { for } 0 \leq t \leq T \text {, }
$$

$$
R_{2}(t)=\text { accounts receivable level at any time } t,
$$

$$
\text { for } T \leq t \leq N \text {, }
$$

$R_{3}(t)=$ accounts receivable level at any time $t$,

$$
\text { for } N \leq t \leq T+N\} \text {. }
$$

We have

$$
\begin{gathered}
R_{1}(t)=0+\int_{0}^{t}\left(\frac{d_{m}}{1+a e^{-b N}}\right) d t=\frac{d_{m} t}{1+a e^{-b N}}, \quad 0 \leq t \leq T \\
R_{2}(t)=\int_{0}^{T}\left(\frac{d_{m}}{1+a e^{-b N}}\right) d t=\frac{d_{m} T}{1+a e^{-b N}}, \quad T \leq t \leq N \\
R_{3}(t)=\int_{t}^{T+N}\left(\frac{d_{m}}{1+a e^{-b N}}\right) d t=\frac{d_{m}(T+N-t)}{1+a e^{-b N}} \\
N \leq t \leq T+N
\end{gathered}
$$


The present value of account receivables carrying cost per year

$$
\begin{aligned}
=\frac{R P}{T} & \left(\int_{0}^{T} R_{1}(t) e^{-k t} d t\right. \\
& \left.\quad+\int_{T}^{N} R_{2}(t) e^{-k t} d t+\int_{N}^{T+N} R_{3}(t) e^{-k t} d t\right) \\
=\frac{R P}{T}\left(\int_{0}^{T}\left(\frac{d_{m} t}{1+a e^{-b N}}\right) e^{-k t} d t\right. & \quad+\int_{T}^{N}\left(\frac{d_{m} T}{1+a e^{-b N}}\right) e^{-k t} d t \\
& \left.+\int_{N}^{T+N}\left(\frac{d_{m}(T+N-t)}{1+a e^{-b N}}\right) e^{-k t} d t\right) \\
= & \frac{R P d_{m} e^{b N-k T}\left(e^{k T}-k T-1\right)}{\left(a+e^{b N}\right) k^{2} T} \\
& +\frac{R P d_{m} e^{b N}\left(e^{-k T}-e^{-k N}\right)}{\left(a+e^{b N}\right) k} \\
& +\frac{R P d_{m} e^{-k(N+T)}\left(1+e^{k T}(k T-1)\right)}{\left(1+a e^{-b N}\right) k^{2} T} .
\end{aligned}
$$

Using (5) and (19), the present value of firm's net profit per year, $Z_{2}(N, T)$ is

$$
\begin{aligned}
& Z_{2}(N, T) \\
& =\left[\frac{(1-f) P d_{m} e^{b N-k(N+T)}\left(e^{k T}-1\right)}{\left(a+e^{b N}\right) k T}-\frac{O}{T}\right. \\
& \quad-\frac{C d_{m}}{1+a e^{-b N}}-\frac{I C d_{m} e^{b N}\left(e^{-k T}+k T-1\right)}{\left(a+e^{b N}\right) k^{2} T} \\
& \quad-\frac{R P d_{m} e^{b N-k T}\left(e^{k T}-k T-1\right)}{\left(a+e^{b N}\right) k^{2} T} \\
& \quad-\frac{R P d_{m} e^{b N}\left(e^{-k T}-e^{-k N}\right)}{\left(a+e^{b N}\right) k} \\
& \left.\quad-\frac{R P d_{m} e^{-k(N+T)}\left(1+e^{k T}(k T-1)\right)}{\left(1+a e^{-b N}\right) k^{2} T}\right] .
\end{aligned}
$$

The necessary conditions for the maximization of $Z_{2}(N, T)$ are

$$
\frac{\partial Z_{2}(N, T)}{\partial N}=0, \quad \frac{\partial Z_{2}(N, T)}{\partial T}=0
$$

which gives

$$
\begin{gathered}
{\left[\frac{P d_{m} e^{b N-k(N+T)}\left(e^{k T}-1\right)(f-1)\left(e^{b N} k+a(k-b)\right)}{\left(a+e^{b N}\right)^{2} k T}\right.} \\
-\frac{C a b d_{m} e^{-b N}}{\left(1+a e^{-b N}\right)^{2}}-\frac{I C a b d_{m} e^{b N-k T}\left(1+e^{k T}(k T-1)\right)}{\left(a+e^{b N}\right)^{2} k^{2} T}
\end{gathered}
$$

$$
\begin{aligned}
- & \frac{R P a b d_{m} e^{b N-k T}\left(e^{k T}-k T-1\right)}{\left(a+e^{b N}\right)^{2} k^{2} T} \\
- & \frac{R P d_{m} e^{b N-k(N+T)}\left(a b e^{k N}+e^{k T}\left(e^{b N} k+a(k-b)\right)\right)}{\left(a+e^{b N}\right)^{2} k} \\
+ & \left(R P d_{m} e^{b N-k(N+T)}\left(e^{b N} k+a(k-b)\right)\right. \\
\times\left(1+e^{k T}(k T-1)\right) & \left.\left.\times\left(\left(a+e^{b N}\right)^{2} k^{2} T\right)^{-1}\right)\right]=0, \\
{[} & \left.\frac{P d_{m} e^{b N-k(N+T)}(f-1)\left(e^{k T}-k T-1\right)}{\left(a+e^{b N}\right) k T^{2}}\right) \\
+ & \left(\frac{O}{T^{2}}\right)-\left(\frac{I C d_{m} e^{b N-k T}\left(e^{k T}-k T-1\right)}{\left(a+e^{b N}\right) k^{2} T^{2}}\right) \\
+ & \frac{R P d_{m} e^{b N-k T}\left(e^{k T}-k T-k^{2} T^{2}-1\right)}{\left(a+e^{b N}\right) k^{2} T^{2}} \\
+ & \frac{R P d_{m} e^{b N-k T}}{a+e^{b N}} \\
+ & \left.\frac{R P d_{m} e^{b N-k(N+T)}\left(e^{k T}-k T-1\right)}{\left(a+e^{b N}\right) k^{2} T^{2}}\right]=0 .
\end{aligned}
$$

The solution of above equations gives the optimal values of $N$ and $T$ for the maximization of $Z_{2}(N, T)$ provided that they satisfy the sufficiency conditions given by

$$
\begin{aligned}
& \frac{\partial^{2} Z_{2}}{\partial N^{2}} \leq 0, \quad \frac{\partial^{2} Z_{2}}{\partial T^{2}} \leq 0, \\
& \left(\frac{\partial^{2} Z_{2}}{\partial N^{2}}\right)\left(\frac{\partial^{2} Z_{2}}{\partial T^{2}}\right)-\left(\frac{\partial^{2} Z_{2}}{\partial N \partial T}\right)^{2} \geq 0 .
\end{aligned}
$$

However, in this case also, it is difficult to solve the necessary conditions analytically in a closed form and also to check the validity of sufficient conditions analytically. Consequently, like the previous case, numerical approach is used to obtain the solution.

Furthermore, combining both of the cases that is, (11) and (20), we get the firm's net profit per year, $Z(N, T)$ as

$$
Z(N, T)=\left(\begin{array}{l}
Z_{1}(N, T), N \leq T \\
Z_{2}(N, T), N \geq T
\end{array}\right) .
$$

Our problem is to find the values of $N$ and $T$ which maximize $Z(N, T)$. To solve the model we solve both of the cases separately and then combine the results to obtain the optimal solution. Due to highly complex and nonlinear form, it is difficult to solve the model analytically in a closed form. However, the model can be solved numerically using LINGO which utilizes generalized reduced gradient algorithm. 


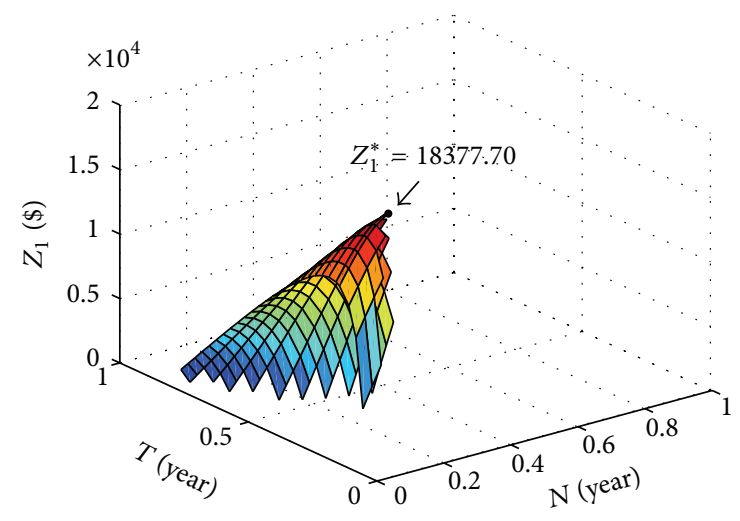

FIGURE 7: Graph of profit function $(N \leq T)$.

\section{Numerical Example}

For numerical illustration, the values of the model parameters are taken as follows: $d_{m}=10,000$ units/year, $a=15, b=5, O=$ $\$ 1000 /$ order, $C=\$ 200 /$ unit, $P=\$ 250 /$ unit, $I=30 \%, R=20 \%$, $k=15 \%$, and $f=4 \%(0.04)$.

Solving the model according to the solution procedure described above, we get

$$
\begin{gathered}
Z_{1}^{*}(N, T)=18377.70 \$ \\
\left.N_{1}^{*}=(0.1461331 \text { (years })=53.33859(\text { days })\right) \\
\left.T_{1}^{*}=(0.1461331 \text { (years })=53.33859(\text { days })\right) \\
Z_{2}^{*}(N, T)=18639.77 \$ \\
\left.N_{2}^{*}=(0.175757 \text { (years })=64.15132(\text { days })\right) \\
T_{2}^{*}=(0.1249569(\text { years })=45.60928(\text { days })) \\
\text { Clearly, } \operatorname{Max}\left\{Z_{1}^{*}, Z_{2}^{*}\right\} \text { is } Z_{2}^{*} . \text { Therefore } \\
N^{*}=N_{2}^{*}=64.15132(\text { days }) \\
T^{*}=T_{2}^{*}=45.60928(\text { days }) \\
Z\left(N^{*}, T^{*}\right)=Z_{2}^{*}=18639.77 \$ .
\end{gathered}
$$

The optimal ordering quantity is $Q^{*}=d_{m} T^{*} /(1+$ $\left.a e^{-b N^{*}}\right)=172.8477$ (Units).

The surface graphs (Figures 7, 8, and 9) of the net profit function $Z(N, T)$ with respect to decision variables $N$ and $T$ have been plotted using MATLAB. The graphs clearly show that at $\left(N^{*}, T^{*}\right)$ the value of $Z\left(N^{*}, T^{*}\right)$ is maximum. Thus, for the given values of parameters in the numerical example, $N^{*}=64.15132$ (days) and $T^{*}=45.60928$ (days) is the optimal solution.

\section{Sensitivity Analysis}

In this section we have studied the effect of changes in the value of input parameters $I, R, f, d_{m}$, and $k$ on the optimal solution. We consider the data as given in the numerical example. It is assumed that all other parameters are known and stationary in the time periods under consideration. The sensitivity analysis is performed by changing one parameter

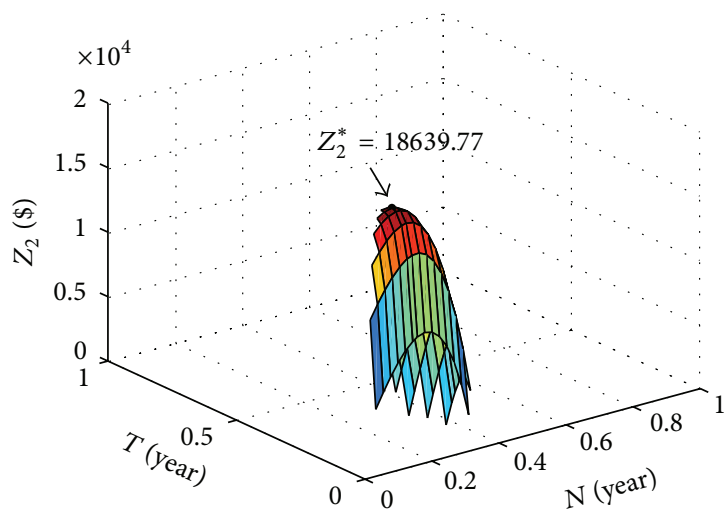

FIGURE 8: Graph of profit function $(N \geq T)$.

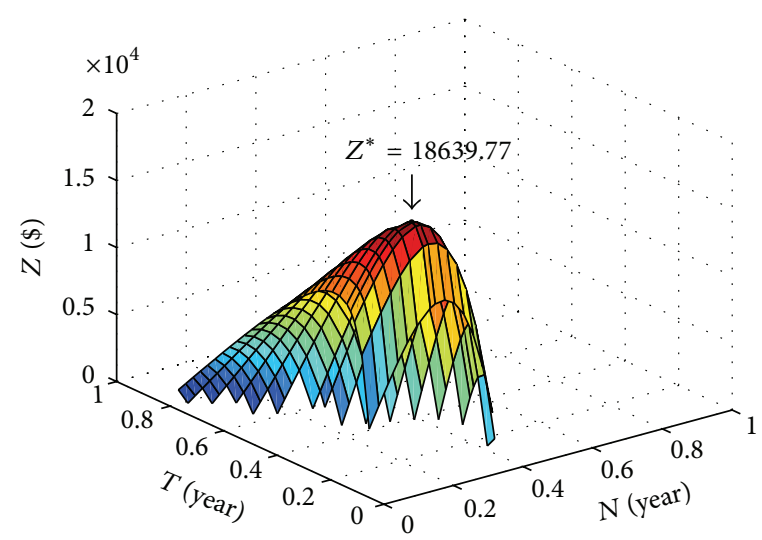

FIGURE 9: Graph of profit function (combined graph of both cases).

at a time and keeping the remaining parameters unchanged. Following tables show the changes in optimal solution for different values of the parameters $I, R, f, d_{m}$, and $k$.

We obtained the following observations and managerial insights from the results of numerical exercise.

(i) From Table 1, it is observed that as the cost of carrying inventory increases the optimal value of credit period, cycle length, and ordering quantity decreases. This is true since as the cost of carrying inventory increases the firm would like to carry inventory in a lesser amount as well as for shorter time duration and in doing so the firm would reduce its demand by decreasing the credit period given to customer. The result is consistent with the properties of EOQ models and also shows that in a credit elastic market the decision of granting credit period to customers is influenced by inventory carrying cost. Therefore, inventory carrying cost should be taken into account by the firm while deciding the level of investment in accounts receivable when demand is influenced by credit period. Results suggest that the firm should follow a stringent credit policy in presence of high inventory carrying cost. It can be that the optimal value of profit decreases as inventory carrying cost increases, which is quite obvious and confirms our expectations.

(ii) Table 2 shows that as accounts receivable carrying cost increases the optimal value of credit period decreases. This 
TABLE 1: Sensitivity analysis with respect to "I."

\begin{tabular}{lcccc}
\hline$I$ & $\begin{array}{c}N^{*} \\
\text { (days) }\end{array}$ & $\begin{array}{c}T^{*} \\
\text { (days) }\end{array}$ & $\begin{array}{c}Q^{*} \\
\text { (units) }\end{array}$ & $Z\left(N^{*}, T^{*}\right) \$$ \\
\hline 0.0 & 74.355 & 72.245 & 308.463 & 25292.82 \\
0.1 & 70.445 & 58.267 & 237.739 & 22627.27 \\
0.2 & 67.133 & 50.597 & 198.599 & 20477.17 \\
0.3 & 64.151 & 45.609 & 172.846 & 18639.77 \\
0.4 & 61.381 & 42.053 & 154.23 & 17018.61 \\
0.5 & 58.754 & 39.367 & 139.938 & 15558.79 \\
\hline
\end{tabular}

TABLE 2: Sensitivity analysis with respect to " $R$."

\begin{tabular}{lcccc}
\hline$R$ & $\begin{array}{c}N^{*} \\
\text { (days) }\end{array}$ & $\begin{array}{c}T^{*} \\
\text { (days) }\end{array}$ & $\begin{array}{c}Q^{*} \\
\text { (units) }\end{array}$ & $Z\left(N^{*}, T^{*}\right) \$$ \\
\hline 0 & 224.857 & 22.087 & 358.225 & 78288.09 \\
0.1 & 123.531 & 32.981 & 240.208 & 30638.88 \\
0.2 & 64.151 & 45.609 & 172.846 & 18639.77 \\
0.3 & 29.558 & 56.087 & 139.622 & 15161.38 \\
0.4 & 7.909 & 64.056 & 121.368 & 14181.72 \\
0.42 & 4.552 & 65.395 & 118.705 & 14124.88 \\
0.44 & 1.443 & 66.66 & 116.277 & 14098.67 \\
0.45 & 0 & 67.256 & 115.164 & 14095.66 \\
0.5 & 0 & 67.256 & 115.164 & 14095.66 \\
\hline
\end{tabular}

is true because as per economic rationale the firm should carry accounts receivable in a lesser amount as well as for a shorter duration as the cost of carrying accounts receivable increases. In doing so the firm should reduce the credit period given to customers so as to reduce the demand. A change in demand would cause a simultaneous change in inventory decisions as per the structure and parameters of the model. The result of increasing accounts receivable carrying cost on inventory decisions indicates that the firm should lengthen its replenishment interval to save on ordering cost in order to maximize its profit. The above analysis confirms that inventory decisions are influenced by accounts receivable carrying cost as well as by credit decisions when demand is dependent on credit period. Therefore, in order to correctly analyze inventory and credit decisions with credit linked demand function the accounts receivable carrying cost must also be integrated in the overall cost-benefit structure of the decision model. The results suggest that the firm should invest less in accounts receivable and hence should follow a stringent credit policy in the situation of high value of accounts receivable carrying cost. Moreover, it can also be observed from Table 2 that the optimal value of credit period becomes zero as accounts receivable carrying cost become very high. This suggests that if the value of accounts receivable carrying cost is very high the firm should go for all cash sales program. Furthermore, the optimal total profit decreases as accounts receivable carrying cost increases, which is quite obvious and confirms our expectations.

(iii) Table 3 shows that as the value of allowance for doubtful accounts increases the optimal credit period decreases. This is quite reasonable because if the firm is
TABLE 3: Sensitivity analysis with respect to " $f$."

\begin{tabular}{lcccc}
\hline$f$ & $\begin{array}{c}N^{*} \\
\text { (days) }\end{array}$ & $\begin{array}{c}T^{*} \\
\text { (days) }\end{array}$ & $\begin{array}{c}Q^{*} \\
\text { (units) }\end{array}$ & $Z\left(N^{*}, T^{*}\right) \$$ \\
\hline 0 & 102.796 & 36.585 & 214.683 & 35406.56 \\
0.01 & 93.712 & 38.462 & 204.412 & 30545.45 \\
0.02 & 84.252 & 40.569 & 193.977 & 26142.17 \\
0.03 & 74.403 & 42.939 & 183.437 & 22180.15 \\
0.04 & 64.151 & 45.609 & 172.846 & 18639.77 \\
0.05 & 53.48 & 48.624 & 162.264 & 15498.73 \\
0.06 & 42.369 & 52.036 & 151.743 & 12732.58 \\
0.08 & 18.719 & 60.323 & 131.091 & 8219.906 \\
\hline
\end{tabular}

expecting to have high rate of default (i.e., bad accounts) it would like to reduce its total credit sales in order to reduce its bad debt expenses and for doing that it should reduce the amount of credit period given to customers. Consequently, there will be a reduction in accounts receivable carrying cost as lesser amount of receivables has to be kept for shorter duration. The saving in accounts receivable carrying cost will contribute in offsetting the cost of bad debt expenses. Further, reduction in credit period leads to a change in demand causing a simultaneous change in optimal inventory decisions as per the structure and parameters of the model. The results show that when higher proportion of sales becomes bad accounts the firm should increase its inventory cycle length for maximizing the profit. The increased cycle length results in less ordering cost. The saving in ordering cost will contribute in offsetting the cost of bad debt expenses. The above analysis and interpretation shows that the inventory decisions are influenced by the value of the allowance for doubtful accounts. This fact becomes even more significant at higher value of bad debt proportion. Thus, the allowance for doubtful accounts must be considered and needs an explicit consideration for making inventory-credit decisions in an inventory system with credit linked demand. The results imply that the firm should devise a stringent credit policy when it is expecting to have higher incidence of bad accounts and the estimation of allowance for doubtful accounts should be done properly. Furthermore, the results indicate that the customer selection criteria have important implications for inventory-credit decisions. Therefore, the character, capacity, and capital of the customers have implications not only for credit decisions but also for inventory decisions and therefore, must be taken into account in inventory control. Moreover, the optimal total profit decreases when the allowance for bad debt expense increases, which is quite obvious and confirms our expectations.

(iv) From Table 4 it can be seen that as the value of maximum achievable demand rate increases the optimal value of credit period increases. This is quite reasonable because if there is a huge market potential, the firm would definitely like to give more credit period in order to capture larger share of it. Although it will cause an increase in bad debt expenses, the loss due to bad debt will be offset by the profit from the paying customers. Thus, if there is a huge market potential for credit demand then the firm should 
TABLE 4: Sensitivity analysis with respect to " $d_{m}$."

\begin{tabular}{lcccc}
\hline$d_{m}$ & $\begin{array}{c}N^{*} \\
\text { (days) }\end{array}$ & $\begin{array}{c}T^{*} \\
\text { (days) }\end{array}$ & $\begin{array}{c}Q^{*} \\
\text { (units) }\end{array}$ & $Z\left(N^{*}, T^{*}\right) \$$ \\
\hline 5000 & 52.755 & 69.114 & 114.319 & 6113.298 \\
8000 & 61.105 & 51.936 & 151.883 & 13414.12 \\
10000 & 64.151 & 45.609 & 172.846 & 18639.77 \\
12000 & 66.313 & 41.099 & 191.726 & 24052.13 \\
15000 & 68.624 & 36.257 & 217.232 & 32425.45 \\
20000 & 71.155 & 30.931 & 254.503 & 46857.89 \\
\hline
\end{tabular}

follow a more liberal credit policy. An increase in credit period results in increase in demand causing a simultaneous change in inventory decisions. It can be seen that firm should order more frequently as well as ordering more quantity if there is a huge credit sales potential in the market. This is because the higher profits generated even after adjusting for bad debts will offset the increase in ordering, inventory holding, and accounts receivable carrying costs as can be seen from the increase in the value of optimal profits. These results are quite obvious and confirm our expectations.

(v) Table 5 shows that the optimal values of credit period and ordering quantity decreases as discount rate increases. This is true because the firm would like to have less investment in inventory and accounts receivable as the opportunity cost of funds increases. In order to do so the firm has to reduce its demand for which it has to decrease the amount of credit period given to customers. A change in demand causes a simultaneous change in inventory decisions according to the structure and parameters of the model. Thus, the results show that inventory-credit decisions are influenced by the time value of money. Furthermore, at a very high value of discount rate the credit period becomes zero. This suggests that in the event of very high opportunity cost of funds the firm should go for all cash sales by investing less in inventory (i.e., smaller ordering quantity) for a shorter duration (i.e., smaller replenishment interval). This is in confirmation with the properties of EOQ model in the present value framework. Also, the value of the optimal profit decreases as discount rate increases, which is quite obvious and confirms the economic logic.

\section{Conclusions}

Offering credit period is a common business practice followed by the firm and through its influence on demand has a significant impact on inventory management. In addition, selling on credit also exposes the firm to the additional dimension of bad debt loss from the customers. Consequently, in this paper an inventory-credit period decision model has been developed within the DCF framework with an explicit consideration of allowance for bad debts along with accounts receivable carrying cost. The demand rate is taken to be logistic function of credit period given to customers. The objective is to maximize the present value of firm's net profit per unit time by optimizing the values of credit period and inventory cycle length jointly. Subsequently, a solution procedure is described to obtain the optimal decisions rules. Numerical example is presented to illustrate
TABLE 5: Sensitivity analysis with respect to " $k$."

\begin{tabular}{lcccc}
\hline$k$ & $\begin{array}{c}N^{*} \\
\text { (days) }\end{array}$ & $\begin{array}{c}T^{*} \\
\text { (days) }\end{array}$ & $\begin{array}{c}Q^{*} \\
\text { (units) }\end{array}$ & $Z\left(N^{*}, T^{*}\right) \$$ \\
\hline 0.05 & 118.521 & 38.608 & 267.252 & 31683.42 \\
0.08 & 99.554 & 40.841 & 231.4 & 26210.58 \\
0.1 & 88.279 & 42.286 & 211.56 & 23456.97 \\
0.15 & 64.151 & 45.609 & 172.846 & 18639.77 \\
0.2 & 44.717 & 48.415 & 145.293 & 15678.04 \\
0.25 & 25.867 & 50.681 & 120.484 & 13785.86 \\
0.3 & 15.771 & 52.45 & 109.815 & 12546.98 \\
0.35 & 4.813 & 53.787 & 97.961 & 11728.88 \\
0.4 & 0 & 53.302 & 91.271 & 11169.74 \\
0.45 & 0 & 51.448 & 88.096 & 10659.41 \\
0.5 & 0 & 49.782 & 85.243 & 10167.61 \\
\hline
\end{tabular}

the model. Finally, sensitivity analysis has been done followed by the discussion on the results. The results are found to be consistent with the economic logic and confirm the model. The proposed model can be used as a framework for the coordination and analysis of inventory and credit period decisions in carrying out working capital planning activities of the firm.

\section{Conflict of Interests}

There is no conflict of interests regarding financial gains for all the authors.

\section{Acknowledgments}

The commercial identities mentioned in the paper such as LINGO and MATLAB software are used only for the numerical analysis of the model discussed in the paper which is only for the academic purpose. The authors of this paper do not have any direct financial relation with the commercial identities mentioned in the paper.

\section{References}

[1] J.-T. Teng, "On the economic order quantity under conditions of permissible delay in payments," Journal of the Operational Research Society, vol. 53, no. 8, pp. 915-918, 2002.

[2] B. G. Kingsman, "The effect of payment rules on ordering and stockholding in purchasing," Journal of the Operational Research Society, vol. 34, no. 11, pp. 1085-1098, 1983.

[3] M. L. Carlson and J. J. Rousseau, "EOQ under date-terms supplier credit," Journal of the Operational Research Society, vol. 40, no. 5, pp. 451-460, 1989.

[4] D. J. Robb and E. A. Silver, "Inventory management under date-terms supplier trade credit with stochastic demand and leadtime," Journal of the Operational Research Society, vol. 57, no. 6, pp. 692-702, 2006.

[5] K. K. Aggarwal and S. P. Aggarwal, "Inventory control with inflation and trade credit," in Operations Research-Theory and Practice, pp. 221-226, Spaniel Publications, New Delhi, India, 1995. 
[6] C. K. Jaggi, K. K. Aggarwal, and S. K. Goel, "Retailer's optimal ordering policy under two stage credit financing," Advanced Modeling and Optimization, vol. 9, no. 1, pp. 67-80, 2007.

[7] C.-H. Su, Y.-L. Ouyang, C.-H. Ho, and C.-T. Chang, "Retailer's inventory policy and supplier's delivery policy under twolevel trade credit strategy," Asia-Pacific Journal of Operational Research, vol. 24, no. 5, pp. 613-630, 2007.

[8] C. K. Jaggi, S. K. Goyal, and S. K. Goel, "Retailer's optimal replenishment decisions with credit-linked demand under permissible delay in payments," European Journal of Operational Research, vol. 190, no. 1, pp. 130-135, 2008.

[9] A. Thangam and R. Uthayakumar, "Two-echelon trade credit financing for perishable items in a supply chain when demand depends on both selling price and credit period," Computers and Industrial Engineering, vol. 57, no. 3, pp. 773-786, 2009.

[10] M. K. Maiti, "A fuzzy genetic algorithm with varying population size to solve an inventory model with credit-linked promotional demand in an imprecise planning horizon," European Journal of Operational Research, vol. 213, no. 1, pp. 96-106, 2011.

[11] C. H. Ho, "The optimal integrated inventory policy with priceand-credit-linked demand under two-level trade credit," Computers \& Industrial Engineering, vol. 60, no. 1, pp. 117-126, 2011.

[12] K. Annadurai and R. Uthayakumar, "Two-echelon inventory model for deteriorating items with credit period dependent demand including shortages under trade credit," Optimization Letters, vol. 7, no. 6, pp. 1227-1249, 2013.

[13] B. C. Giri and T. Maiti, "Supply chain model with priceand trade credit-sensitive demand under two-level permissible delay in payments," International Journal of Systems Science, vol. 44, no. 5, pp. 937-948, 2013.

[14] N. H. Shah, D. B. Shah, and D. G. Patel, "Optimal credit period and purchase quantity for credit dependent trended demand," OPSEARCH, 2014.

[15] S. H. Kim and W. R. Feist, "Examination of the equivalent relationship between the two credit policy decision approaches: the opportunity cost and NPV approaches," The Financial Review, vol. 30, no. 4, pp. 711-737, 1995. 


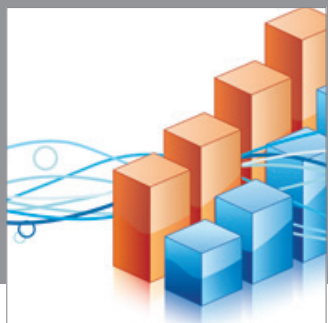

Advances in

Operations Research

mansans

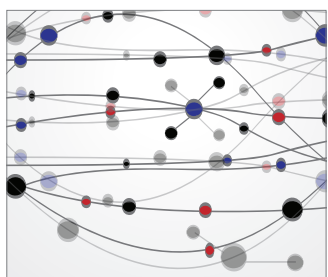

The Scientific World Journal
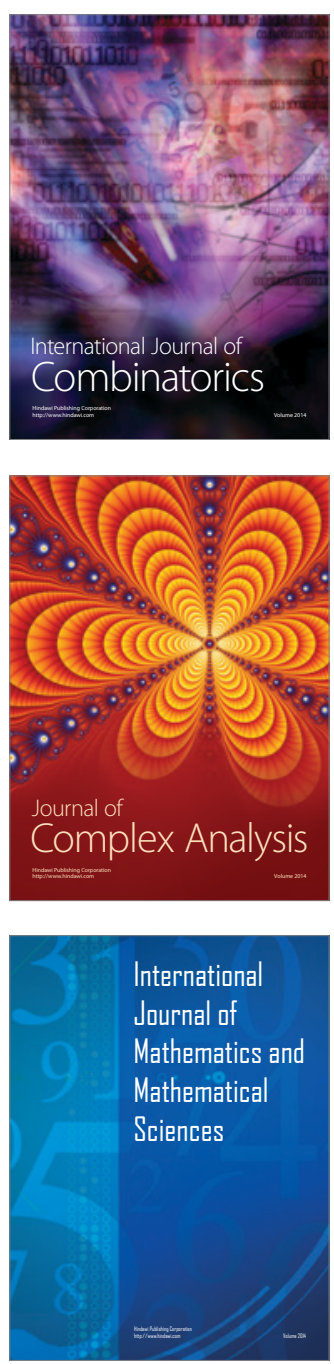
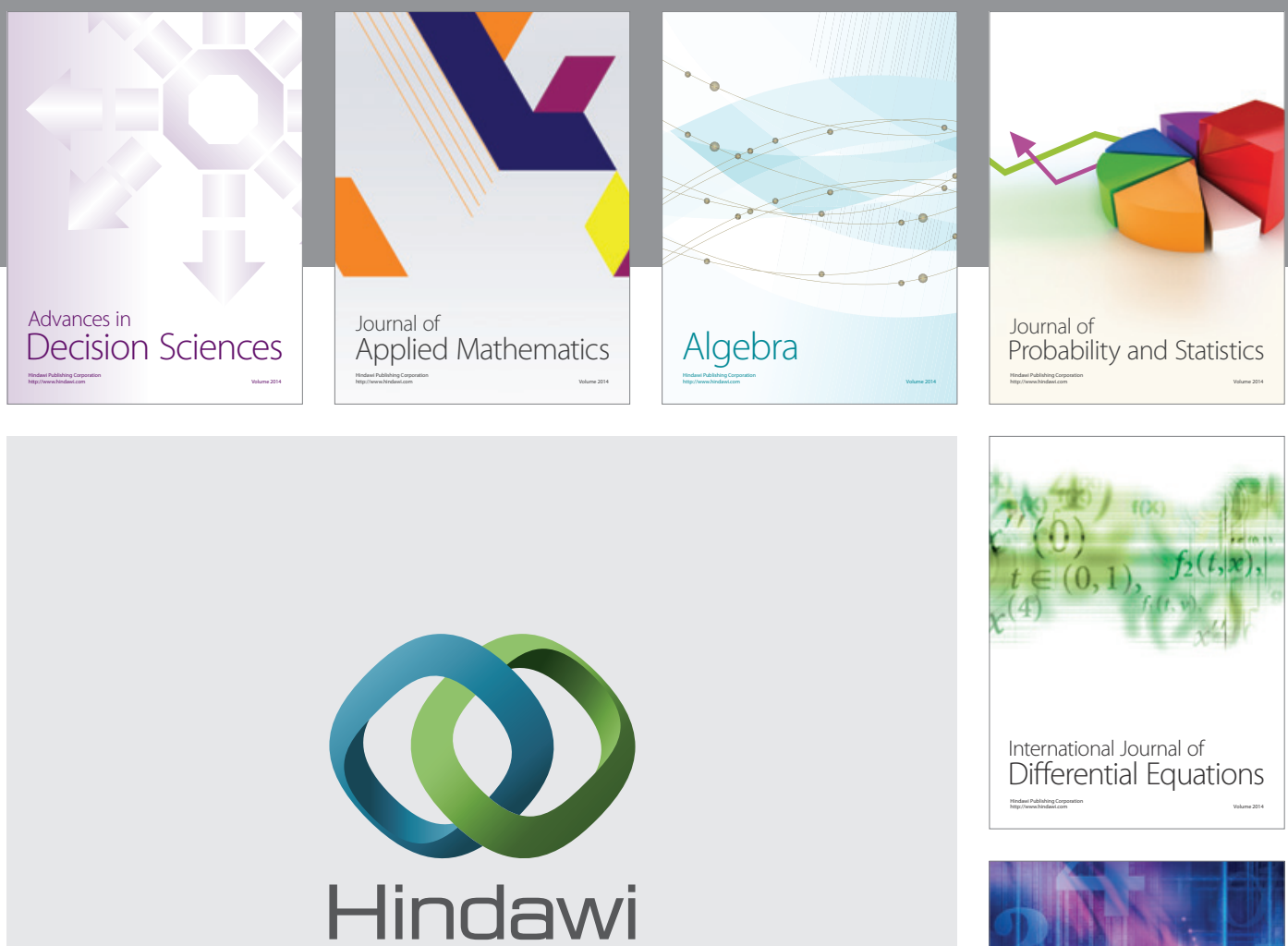

Submit your manuscripts at http://www.hindawi.com
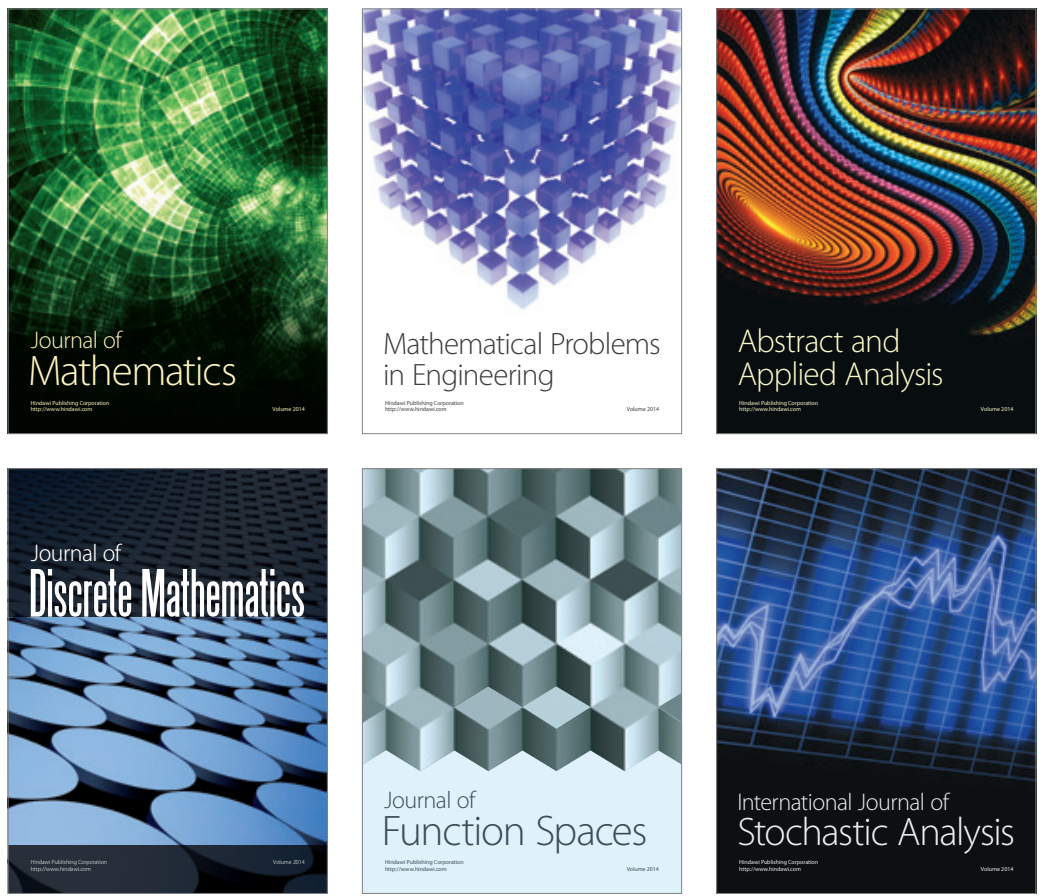

Journal of

Function Spaces

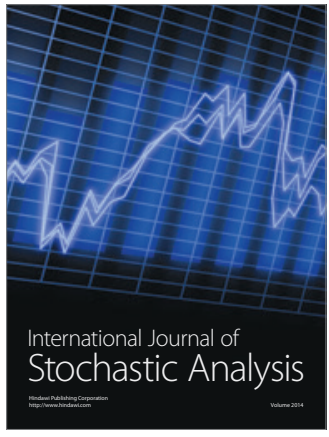

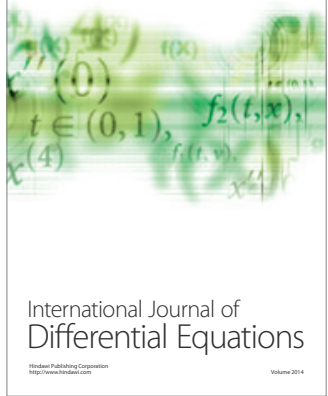
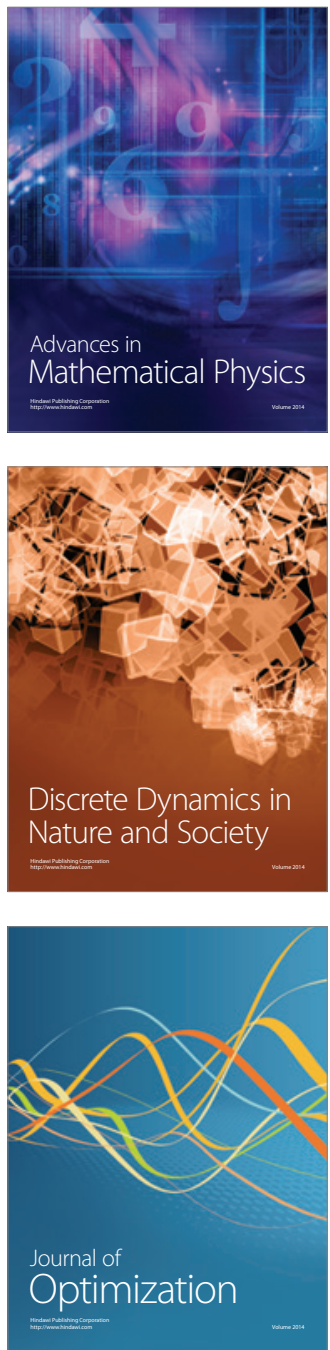